Revista Iberoamericana, Vol. LXXII, Núms. 215-216, Abril-Septiembre 2006, 379-394

\title{
ALEGORÍAS DEL REPUDIO: POLÍTICAS SUBALTERNAS Y DOMINANTES EN LA REVOLUCIÓN MEXICANA
}

POR

\author{
BRIAN GOLLNICK \\ University of Iowa
}

Desde hace una década, un grupo de investigadores organizados por John Beverely e Ileana Rodríguez ha desarrollado un proyecto para la literatura latinoamericana inspirándose en los trabajos de Ranajit Guha, los ensayos de Gayatri Spivak y otros investigadores que han intervenido en los estudios del subalterno para la India. El principal resultado de este subalternismo literario ha sido una metacrítica de los intelectuales y su función en justificar jerarquías sociales. ${ }^{1}$ Al decir de Beverley, el trabajo del subalternismo cultural es elaborar "una crítica de las formas del conocimiento académico tales como nosotros las practicamos; es decir, una crítica de nuestra complicidad en la producción y reproducción de relaciones sociales y culturales de desigualdad” (“Im/ possibility" 61). ${ }^{2}$ Sin embargo, un grupo de historiadores, como Florencia Mallon y Gilbert Joseph, también ha adaptado el proyecto subalternista al contexto latinoamericano. Ellos se inspiran en Guha y los planteamientos de Gramsci sobre las clases subalternas y proponen una renovación de la historiografía latinoamericana, tomando principalmente el caso de México. Hasta la fecha, las publicaciones de los historiadores se acercan más a la formación de una metodología compartida, mientras el grupo literario emerge de una crisis disciplinaria en las humanidades que resiste concreciones metodológicas. ${ }^{3}$ Recientemente, el grupo literario anunció el final de su colaboración organizada, pero

\footnotetext{
${ }^{1}$ De ahí que una de las reservas más insistentes a esta crítica provenga de las diferencias de contexto entre Latinoamérica y la India decimonónica. Véase al respecto las intervenciones de Mabel Moraña, Víctor Bravo y Hugo Achugar.

${ }^{2}$ Todas las citas en inglés aparecen traducidas por el autor, salvo una cita a Arturo Warman que se ha dejado en inglés para evitar la re-traducción de un texto ya traducido del español.

${ }^{3}$ Las influencias históricas empiezan con Eric Hobsbaum y sus estudios sobre la rebelión rural, pero pasan rápidamente al trabajo de EP Thompson sobre la formación de la clase obrera en inglaterra y los sugestivos textos de Carlo Ginzburg sobre la historia medieval. Se incluye también la escuela de historia local organizada alrededor de Luis González y González en México, junto con algunas vertientes de la historiografía poscolonial y nuevos acercamientos a la formación de sujetos populares, sobre todo en términos de los medios masivos teorizados en Latinoamérica por Jesús Martín Barbero. Resúmenes de estas influencias pueden encontrarse en los artículos de Mary Kay Vaughn y Alan Knight.
} 
todavía no se ha esclarecido el destino final del proyecto ni su relación con el grupo de historiadores. ${ }^{4}$

Los desencuentros entre las dos versiones existentes del subalternismo latinoamericano pueden atribuirse sólo parcialmente a diferencias entre campos de estudio, y sorprende la falta de diálogo. Ha habido críticas entre Beverley y Mallon, pero aún en estos intercambios no se ha dado un debate sobre las propuestas específicas de cada proyecto. ${ }^{5}$ En este ensayo, ofrezco un análisis literario que trata de tender un puente hacia los trabajos históricos, en particular con los vocabularios de Mallon. Me acerco al trabajo de ella porque quiero rastrear ciertas formas de agencia popular a través de la literatura y sugerir así un renovado proyecto para los estudios literarios del subalterno en América Latina.

Proyectos subalternistas

Tanto los historiadores como los críticos literarios deben su interés subalternista a las crisis políticas de la academia en los Estados Unidos. Después de la guerra fría, los historiadores han propuesto una investigación nueva sobre la política popular, especialmente en cuanto a la formación del estado. También quieren rellenar un vacío ideológico en el proyecto intelectual de la izquierda después de la caída del socialismo estatal (Mallon, "Promise” 1491). Los críticos literarios se enfrentaron con esta misma coyuntura política, pero, además, buscaron responder a las "guerras culturales” de los ochenta en los Estados Unidos y la creciente institucionalización de los estudios culturales dentro del profesionalismo intelectual. ${ }^{6}$ Frente a esta cooptación de lo que se consideraba un proyecto intelectual de vanguardia, los subalternistas literarios propusieron una renovada crítica del saber académico. Los dos proyectos subalternistas para Latinoamérica se derivan así de la misma crisis de la izquierda académica, y el debate está principalmente en sus acercamientos al conocimiento institucional.

El grupo literario publicó su manifiesto en 1993 (Latin American American Subaltern Studies Group), pero al juicio de Mallon, este “Founding Statement” no plantea métodos para realizar su objetivo: decentralizar el estado en la historia latinoamericana ("Promise" 1505). Ella sugiere coordinar la reflexión historiográfica con el trabajo de campo e investigación en los archivos. Así se pretende precisar la política popular, siguiendo la intención trazada por Gramsci de estudiar todas las formas de iniciativa subalterna y mejorar las posibilidades de construir "el partido jacobino de la izquierda: el partido

\footnotetext{
${ }^{4}$ Una muestra de las diferencias o tensiones internas al grupo literario puede verse en el anuncio de Ileana Rodríguez que el proyecto de estudios del subalterno para América Latina se había desbandado y la sorprendida respuesta de Robert Carr.

${ }^{5}$ Véase las críticas de Mallon a Beverley ("Promise” 1504-06) y las respuestas de Beverley (Subalternity 34-37).

${ }^{6} \mathrm{El}$ desengaño de Beverley con los estudios culturales se hizo público en su artículo, "Cultural Studies.” Recientemente, Beverley ha matizado un poco su perspectiva al plantear que dentro de las instituciones académicas, el crecimiento de los "estudios culturales" representa una apertura que, cuando interrogada desde la perspectiva de los estudios del subalterno, puede formar parte de un nuevo proyecto de la izquierda (véase Subalternity and Representation 115-32, especialmente 13032).
} 
hegemónico con un verdadero liderazgo” (Mallon, “Promise” 1496, 1510). Para Mallon, el "Founding Statement” no alcanza esta meta porque se limita a una metacrítica, pasando por alto el aspecto directamente político de Gramsci.

El problema que Mallon señala se debe en parte a simple un error cronológico: el grupo literario publicó su "Founding Statement" antes de formular trabajos dentro del proyecto anunciado y su manifiesto no pudo ser sino abstracto. Pero Mallon acierta en señalar que las influencias del grupo literario tienden fuertemente a la desconstrucción. José Rabasa, integrante del grupo literario, ha notado lo mismo cuando observa que "el proyecto de estudios del subalterno para América Latina demuestra la influencia de la crítica de Spivak a Guha y el proyecto historiográfico en general” (199) más que una influencia directa de Guha y Gramsci. El "Founding Statement” es así un producto de la segunda fase del grupo de estudios del subalterno sobre la India, cuando el proyecto viró hacia una crítica del discurso intelectual. ${ }^{7}$ Para los críticos literarios, esta reflexión se justifica para América Latina a través de Ángel Rama y el precepto de que a nivel de las instituciones sociales, la cultura escrita siempre ha formado parte de la dominación clasista. Hablando de La ciudad letrada, Beverley afirma que "si la literatura ... estaba funcionalmente implicada en la formación tanto de las élites coloniales como las poscoloniales en América Latina, nuestra propuesta [anterior] que la literatura era un vehículo a través del cual las voces populares podrían encontrar mayor expresión ... se puso en duda" (Subalternity 8). La respuesta frente a esta duda era criticar la literatura como una práctica social y trazar la ausencia del subalterno en los discursos de la ciudadanía cultural. En esta crítica, los discursos de la élite no pueden representar al subalterno sin sublimarlo a la ideología dominante. Rabasa, glosando una formulación de Doris Sommer, lo presenta como la necesidad de respetar el silencio (200-201). De ahí que el objetivo del proyecto sea seguir con un aspecto del proyecto de Rama: completar la desconstrucción (valga la paradoja) del discurso literario-intelectual como una herramienta del poder. ${ }^{8}$

Mallon no acepta este dilema epistemológico. Ella reconoce los límites del discurso intelectual dominante, pero para ella el objetivo no es silenciar al intelectual frente a la imposibilidad de representar al subalterno, sino llenar los silencios donde la historia dominante no ha permitido que el subalterno ocupe la posición de sujeto. Es en este sentido que entiendo su defensa del trabajo de campo y los archivos: si la historia dominante se ha construido marginalizando la perspectiva de los dominados, hay que remitirse a la documentación que hasta la fecha se ha excluido de la memoria oficial. No se trata de llegar a una visión completa de la agencia subalterna, sino de registrar la historia popular desde otro nivel de la censura institucional. Aquí el debate entre los historiadores y los literatos se centra en los mecanismos del control discursivo. Para el proyecto literario, la ciudad letrada construye jerarquías sociales con las prácticas amplias del alfabetismo y la palabra escrita se plantea casi como una epistemología del poder. Para el proyecto historicista, la ciudad letrada opera a través de las instituciones que controlan la articulación social del alfabetismo, como la educación y la imprenta. Al margen de estas

\footnotetext{
${ }^{7}$ Sobre los cambios en el grupo de Guha, véase Chaturvedi (vii-xix).

${ }^{8}$ Véase la perspicaz reseña de Subalternity and Representation por Misha Kokotovic para un acercamiento alternativo a Rama y La ciudad letrada.
} 
instituciones, los historiadores buscan depositorios alternativos de la memoria colectiva, como la tradición oral y nuevas fuentes escritas, para reconstituir elementos de la agencia popular.

La literatura se diferencia claramente de los documentos de archivo, y esto podría explicar la diferencia entre acercamientos. Sin embargo, algunas de las categorías de Mallon también podrían servir para situar la literatura en un proyecto del subalternismo literario. Por ejemplo, Mallon distingue entre el "proceso" y el "resultado" hegemónico. ${ }^{9}$ El resultado hegemónico, o lo que yo llamaría la formación hegemónica (para enfatizar su relativa estabilidad histórica), describe aquel momento en que una facción o una coalición llega al poder combinando la fuerza y la persuación. Tal formación sólo puede surgir cuando se logra "incorporar de manera parcial las aspiraciones políticas o los discursos de quienes apoyan el movimiento” (Mallon, Peasant 7). Pero la incorporación de demandas populares nunca es más que parcial y en el momento de la formación hegemónica "las contribuciones y luchas de grupos subalternos serán reorganizadas y redefinidas, ocultadas y parcialmente enterradas” (Peasant 7). El proceso hegemónico es la articulación de este resultado en la vida diaria con "una serie de procesos continuos e imbricados a través de los cuales el poder y el conocimiento son disputados, legimitizados y redefinidos en todos los niveles de la sociedad” (Peasant 6). La formación hegemónica describe así los límites oficiales de los discursos sobre la identidad social y la historia. El proceso hegemónico se da de manera cotidiana, pero su poder contestatorio varía con la política dominante. En momentos revolucionarios, ésta pierde su aspecto hegemónico al depender casi totalmente de la fuerza, pero tales crisis abren posibilidades de redefinir la incorporación de demandas populares.

En general, la literatura latinoamericana pertenece a la formación hegemónica. Circula entre un sector reducido y sólo alcanza una cotidianidad restringida. Dado su vínculo a un sistema de educación elitista, la literatura ocupa un sitio exclusivo en el proceso hegemónico y, como Rama señala, ha sido recalcitrante en articularse con la cultura popular. ${ }^{10}$ Sin embargo, esto no le niega una posición significativa si los sectores letrados prestan un servicio importante a la política dominante. Además, el privilegio no excluye que la literatura registre cambios en la cultura oficial, y esto permite que la literatura mida el balance de fuerzas dentro de un proceso hegemónico que está socavando la ideología dominante o estableciendo los linderos de una nueva formación hegemónica. Además, la literatura ha participado en el proceso hegemónico de los sectores dirigentes -los letrados- y la función de éstos en la hegemonía hace de la literatura un sitio viable para rastrear ciertas articulaciones de la política popular.

LA REVOLUCIÓN DEL SUR

La nueva formación hegemónica establecida después de la revolución mexicana dio lugar a una nueva literatura basada en la "novela de la revolución”. Esta narrativa

\footnotetext{
${ }^{9}$ En esto Mallon sigue el vocabulario de William Roseberry.

${ }^{10}$ Aquí estoy proyectando el vocabulario de Mallon sobre la división que Rama señala entre la “ciudad letrada” y la "ciudad real” (Rama 45-52).
} 
prioritizaba la experiencia villista en el norte del país, casi sin representar el Ejército Libertador del Sur bajo Emiliano Zapata. En su estudio sobre la imagen pública de los líderes revolucionarios, Ilene O’Malley especula que la ausencia de representaciones literarias o cinematográficas del zapatismo se debe a que Zapata no gozaba de gran carisma entre las clases medias. Mientras la figura de Zapata conectaba el nuevo régimen con el campesinado, los valores del movimiento zapatista -la restitución de tierras comunales y protección para la agricultura de subsistencia-no ayudaron a establecer la legitimidad del gobierno entre los sectores urbanos y burgueses, los principales productores y consumidores de la literatura.

También resulta importante señalar la diferente función de los intelectuales villistas y zapatistas. Friedrich Katz ha notado que ni Villa ni Zapata sentían mucha simpatía por los intelectuales, pero el movimiento villista los utilizaba en tareas levemente más amplias que el zapatista (280-81). El villismo contaba así con más intelectuales que experimentaron directamente el movimiento y que aspiraron a desempeñar el papel tradicional del letrado: fijar y diseminar un plan general para las aspiraciones del grupo. Estos intelectuales incluían destacados narradores, como Mariano Azuela y Martín Luis Guzmán. ${ }^{11}$ En cambio, los asesores zapatistas provenían de la pequeña burguesía y aspiraban a trabajos políticos y administrativos más que culturales.

Gregorio López y Fuentes (1897-1966) conoció la lucha armada como un soldado carrancista y participó en la defensa de Veracruz frente a la invasión estadounidense en 1914. Llegó a ser reconocido como narrador cuando publicó El indio (1935), pero se desarrolló como escritor en los años veinte. Tierra (1932), su cuarta novela, resultaría prescindible hoy si no fuera la única obra directamente sobre el zapatismo que llegó a formar parte del canon oficial de la novela de la revolución. Tierra se divide en secciones denominadas por años, abarcando el período de 1910 a 1920, y con este marco López y Fuentes narra la experiencia de la revolución en una hacienda de Morelos - la comarca de Zapata. Así es que la novela hace de la historia regional una narración accesible a un público urbano y educado que hubiera conocido a Zapata principalmente a través de la propaganda negativa en la prensa capitalina. Con Tierra, López y Fuentes contribuye a un cambio en la política dominante. Ésta, desde el gobierno de Álvaro Obregón (1920-24), quería rescatar a Zapata para una alianza estratégica con el movimiento agrario. Tal alianza contribuyó a derrocar a Carranza en 1919 y ayudó a consolidar el nuevo gobierno, pero con la presidencia de Plutarco Elías Calles (1924-28), el estado se fortaleció más en el movimiento obrero que en el campesinado. Esto implicó limitar la proyección ideológica de Zapata y controlarlo como el emblema del estado. De ahí que se enfatizara una imagen paternalista de Zapata como caudillo (O’Malley 52-56). La novela de López y Fuentes se inserta en esta segunda apropriación ideológica de Zapata.

La participación de intelectuales en las campañas publicitarias de Calles puede notarse en textos como la biografía de Zapata que el poeta Germán List Arzubide publicó en 1927, Emiliano Zapata (exaltación). List Arzubide formó parte del grupo “estridentista”

\footnotetext{
${ }^{11}$ La participación más amplia de intelectuales villistas no debe confundirse con un apoyo intelectual al movimiento, ya que casi todas las figuras que colaboraron directamente o indirectamente en la División del Norte acabaron escribiendo críticas de la insurgencia popular.
} 
que fomentó una estética futurista junto con una ideología nacionalista y patriarcal. El libro de List Arzubide tiene más de hagiografía que de biografía y construye a Zapata como una figura mesiánica: “Su voz ordenaba y nadie le contradijo nunca. Más que en aquellos millares de combatientes, parecía gobernar sobre sus espíritus incendiados de fe. Como un rey de otrora, manejaba a sus hombres como los miembros de su cuerpo" (43). El liderazgo de Zapata se presenta como vertical y concentrado en su carisma personal "nadie lo contradijo nunca". El lenguaje enaltecido se dirige claramente a un lector educado y urbano, y la imagen de "un rey de otrora" invoca a una figura patriarcal, benévola y todopoderosa, lo cual concuerda perfectamente con el proyecto del estado. Al decir de O’Malley, hacia finales de los años veinte, los discursos oficiales preferían representar a Zapata como "un hombre superior que ayuda a la gente humilde que depende de él, no de ellos mismos, para protección y liderazgo”. Como ella también nota, esta imagen eleva al líder para disminuir a sus seguidores: "el gobierno debería guiar y el pueblo, seguirlo” (60). Al igual que la imagen que List Arzubide ofrece de los miembros del cuerpo obediciendo a Zapata, el discurso del caudillo patriarcal caracteriza al estado autoritario como una expresión orgánica del pueblo, sin atribuir una agencia propia a las clases populares.

Tierra es un producto de este ambiente ideológico que la biografía de List Arzubide y López y Fuentes reproduce en la imagen paternalista de Zapata. También cabe señalar que ambos libros se basan en un error histórico: plantean a los campesinos de las haciendas como el sector motriz de la revolución agraria. En realidad, el movimiento zapatista se gestó entre los pueblos autónomos amenazados por las plantaciones de caña, que se habían expandido sobre los terrenos tradicionales de las comunidades vecinas desde finales del siglo XIX (Womack 37-66). El zapatismo fue en toda su trayectoria un movimiento de pequeños productores, no del proletariado rural en sí. Más que un error, sin embargo, esto es un elemento central en la raigambre ideológica e histórica de la novela de López y Fuentes.

Las secciones iniciales de Tierra establecen el antiguo régimen, enfatizando su estancamiento: "Es atardecer de día sábado y los peones ... han acudido a tratar.... El amo recibe a sus hombres. Tiene todo el continente de un cacique. Los peones casi se arrodillan” (261). Tanto López y Fuentes como List Arzubide presentan a Zapata salvando una población sumisa que ha sufrido bajo una clase terrateniente poco cambiada desde la colonia. Esto permite concebir la revolución como un éxito de la modernidad sobre estructuras sociales anticuadas, y el retrato de un mundo sin cambio esconde los procesos de modernización que los hacendados en Morelos llevaban a cabo desde las últimas décadas del siglo xıx. En gran medida, la revolución consolidó una estructura política más estable para seguir con un proyecto económico semejante, pero la imagen de una lucha entre el desgastado sistema colonial y un nuevo régimen modernizador permite soslayar cualquier continuidad entre la economía porfiriana y el gobierno pos-revolucionario. Este elemento ideológico justifica el estado pero también promueve la percepción de una coincidencia de intereses entre el campesinado y una burguesía que quería entenderse como el principal promotor de la modernidad.

Lo notable de la novela es la manera en que López y Fuentes trata la agencia popular. Al final de la primera sección, Antonio, un peón que se convierte después en jefe zapatista, 
es condenado al servicio militar por asaltar al administrador de la hacienda. Después, en la fiesta del pueblo, llegan dos cantantes que entonan “La Leva,” un corrido que recuerda a Antonio: "se alternan, relatando las peripecias de todos aquellos a quienes se han llevado de reclutas. Son recuerdos de las requisas de hombres que se hicieron hace muchos años para combatir a los americanos y después a los franceses” (266-67). Aquí la novela registra una historia oral vinculada a la invasión estadounidense (1846-48) y la intervención francesa (1863-67). Es un detalle crucial porque, de acuerdo a Mallon, el servicio militar en estos conflictos era uno de los principales puntos de articulación entre la élite regional y los líderes comunitarios (Peasant 23-62). Especialmente durante la intervención francesa, la victoria se ganó en las negociaciones entre estos sectores como un proceso hegemónico, terminando con la incorporación parcial de las demandas subalternas al nacionalismo liberal. Como enfatizan Mallon y también Womack, el servicio militar era un detonante de la identidad regional en Morelos y uno de los puntos centrales donde el subalterno había ejercido cierta agencia en la formación del estado. La memoria de esta agencia se conservó como una gestación autónoma frente al poder. Cuando la revolución se organizó en Morelos, no fue bajo un caudillo carismático, como quiere List Arzubide, sino bajo varios líderes que canalizaron estas tradiciones. Sin embargo, López y Fuentes circunscribe esta historia popular: "los trovadores relatan que llegaron las fuerzas del gobierno, que se citó a todos los jóvenes solteros y que de ellos se llevaron a los mejores. En cada final de estrofa hay algo así como un sollozo, tal vez porque el autor no pudo transcribir de mejor manera el llanto de las madres deshijadas” (267). En vez de funcionar como el archivo de una identidad colectiva vinculada a la agencia popular, el servicio militar se convierte en un melodrama del sufrimiento individual apropriado implícitamente para la esfera privada.

Dada la incorporación del zapatismo al estado, la biografía de List Arzubide y Tierra demuestran cómo los intelectuales y el discurso literario se hacen cómplices de una formación hegemónica. Ambas obras promueven una identificación ideológica de dos sectores letrados -la burguesía y la pequeña burguesía- con la emergente imagen oficial del campesinado. Además, la novela demuestra cómo la literatura puede mimetizar los límites que la ideología dominante quiere imponer en la expresión de la historia popular a fin de que "las contribuciones y luchas de grupos subalternos" efectivamente aparezcan "reorganizadas y redefinidas, ocultadas y parcialmente enterradas", para reiterar a Mallon. Sin embargo, no toda la literatura funciona tan fielmente dentro de las exigencias del estado ni a tanta distancia de la política subalterna.

EL GOBIERNO NO TIENE MADRE

En su reconocido estudio del zapatismo, John Womack describe el último intento que Carranza hizo para negociar con Zapata, en septiembre de 1914. El intento fracasó, pero dos de los representantes carrancistas, Antonio Villareal y Luis Cabrera, redactaron un informe que enfatiza la intransigencia de Zapata y sus asesores. De acuerdo a Villareal y Cabrera, Zapata y sus consejeros insistieron en la supremacia del Plan de Ayala, el principal manifiesto zapatista: "la condición previa y sine qua non para cualquier arreglo tenía que ser la sumisión del Primer Jefe [Carranza] y de los generales constitucionalistas 
al Plan de Ayala, firmándose al efecto una acta de adhesión en que se aceptara el plan mencionado en todas sus partes” (Magaña, vol. V, 87). Villareal y Cabrera trataron de coordinar una conferencia de delegados, pero Zapata reiteró la demanda que Carranza se subordinara al ejército sureño. El fracaso de estas negociaciones llevó eventualmente a la muerte de Zapata a manos de agentes carrancistas en 1919, tras varios años más de conflicto. En parte, Womack atribuye la intransigencia de Zapata a la ambición personal de sus asesores y la falta de confianza que Zapata sentía al tratar la política nacional (2045). Sin embargo, Womack también señala otra dinámica en la política popular de Morelos en 1914, una dinámica que podría llamarse el repudio.

Womack sugiere que un acuerdo entre Zapata y Carranza nunca estaba en tela de juicio: "para los zapatistas, que incluían a toda la población del estado, las pláticas en Cuernavaca nunca habían sido negociaciones, sino pretextos para la confirmación final de sus esperanzas y miedos” (211). En esto, la frustración de los delegados carrancistas apunta hacia una profunda diferencia en la concepción del poder político. Villareal y Cabrera quieren establecer contactos entre dos líderes que pueden tratarse por encima de las diferencias entre sus movimientos y a espaldas de sus bases de apoyo. Resulta imposible entablar tal diálogo porque Zapata opera con una idea antagónica de la representatividad: Villareal y Cabrera quieren negociar bajo el precepto de que la política es el arte del compromiso y su objetivo es llegar al beneficio mutuo. Se frustran al descubrir que Zapata no está dispuesto al quid pro quo ni al "egoísmo ilustrado" implícito en esta concepción de la política. Con la demanda zapatista de que Carranza se subordine al Plan de Ayala, Villareal y Cabrera descubren que la autoridad de Zapata es diferente del poder político en el sentido que ellos manejan el término. Zapata basa su legitimidad en la pertenencia al lugar, es decir, en las relaciones de parentesco, la participación en los ritos de la comunidad y el sufrimiento compartido. Womack presenta los resultados de este sistema así: "la gente del campo en Morelos actuaba a través de Zapata; y cuando ellos se distanciaron de Carranza con asco, desconfianza y desengaño, igualmente, como uno de ellos y como su jefe, Zapata tenía que distanciarse también” (210). Cuando Zapata y sus asesores imponen condiciones imposibles para las negociaciones, no sólo se rehúsan al diálogo. Más que nada, anuncian su rechazo de las reglas con que Carranza quiere definir el juego político para separar la dirigencia zapatista de sus bases y cooptar a los líderes. La actitud obstinada de Zapata es, en realidad, su repudio frente a este tipo de maniobra y frente a un sistema que, pese a sus promesas democráticas, sólo había excluido las clases populares del proceso político y para mantener a los campesinos en una posición subordinada.

El repudio es este rechazo que el subalterno expresa frente a las reglas con las cuales el sistema político dominante enmarca y limita una negociación para convertirla en cooptación. En esto, el repudio registra el desencuentro entre la política dominante y la política popular. Más específicamente, este desencuentro señala la medida en que la política subalterna rechaza la representación liberal. Como Arturo Warman observó, "For Zapatismo, popular sovereignty did not mean formal and representative democracy in which sovereignty is exercised electorally, but it meant a direct democracy, permanently located in the social units that controlled the land, had the autonomy to organize production, and exercised political-military functions” (331). Womack se refiere a este 
sistema como la utopía del municipio autónomo, y en ella la autoridad de Zapata se deriva de su posición vivida en la comunidad, no de una constitución escrita que especifique representantes legimitizados a través de elecciones para negociar e implementar cambios a nombre de sus electores. Fue precisamente esta segunda forma de política liberal lo que había fallado reiteradamente en Morelos, y la población lo rechazó como un sistema distanciado, carente de control popular y sujeto a la corrupción.

El conflicto entre las formas de representación populares y las formas burguesas implica que en el momento del repudio, el sistema liberal no puede negociar con el subalterno porque en este momento el subalterno no está interesado en promover una participación política dentro de las reglas del juego liberal. Con el repudio, el subalterno más bien quiere expresar su indignación frente a los abusos del poder y la falta de legitimidad en el gobierno. Es en este momento que las demandas populares son más propicias a parecer irrazonables o extravagantes y también es en este momento que las respuestas de la élite son más limitadas. Pero a pesar este aparente desinterés del subalterno en remedios concretos, el repudio no puede surgir sino como una consecuencia de la organización política del pueblo, como se puede notar en Morelos durante el auge del zapatismo (Womack 224-55). De ahí que el repudio señale una historia de agencia popular frente a un sistema que no ha logrado la incorporación efectiva de las demandas del subalterno: el subalterno rechaza las reglas del juego político tradicional porque la experiencia indica que este sistema sólo ofrece un callejón sin salida. El repudio surge de este recrudecimiento en la lucha por la hegemonía y señala que el subalterno ha llegado a aprehender la necesidad de llevar su postura frente al poder liberal más allá de los compromisos establecidos. El repudio es así tanto un registro como la causa de una debilidad crucial en una formación hegemónica que está sufriendo profundos cambios en su sistema de canalizar y resolver los conflictos entre sectores socialmente antagónicos.

Es importante reconocer, sin embargo, que el repudio no representa una modalidad fija de la política subalterna, sino un momento extremo en el proceso de lucha y diálogo. Cuando Villareal y Cabrera llegaron al cuartel general de Zapata, los campesinos de Morelos ya habían derrotado dos campañas de tierra arrasada (una bajo Díaz y la otra bajo Huerta). En el interludio de paz, no habían visto más iniciativa del gobierno que una serie de reformas no realizadas. Así es que cuando Cabrera y Villareal sugerían que Carranza “adoptara el Plan de Ayala en sus principios fundamentales, incorporándolos en un arreglo o convenio” (Magaña, vol. 5, 88), resulta fácil entender la desconfianza que Zapata sentía frente a más promesas y declaraciones vacías. Desde luego, cuando la frustración del subalterno se combina con una conciencia elevada de su poder y una experiencia directa del éxito, el repudio implica una preferencia por el enfrentamiento y el rechazo de "convenios." De ahí que del repudio lleve comúnmente a la violencia o por lo menos a una falta de comunicación que se expresa en la burla, el desprecio, el cruce de signos o ciertas formas agresivas del silencio. Dentro de la literatura mexicana, no es la novela de la revolución que mejor haya captado estas dinámicas, sino la obra de Juan Rulfo.

La relación filial es uno de los ejes centrales en Rulfo, especialmente en Pedro Páramo, donde Juan Preciado anuncia inmediatamente su búsqueda por la imagen de su padre. Por supuesto Abundio, el arriero que lleva a Juan Preciado al pueblo de su padre, también es hijo de Pedro Páramo, y quizás no sería exagerado leer en estos dos personajes 
una alegoría de otras relaciones sociales, como las de la clase terrateniente y el campesinado. Al principio Abundio es una voz sin atribución que responde a Juan Preciado: ““¿Y cómo se dice usted que se llama el pueblo que se ve allá abajo?' 'Comala, señor' 'Está seguro de que ya es Comala?' 'Seguro, señor’” (180). Después esta voz cobra un sujeto -“'Y a qué va usted a Comala, si se puede saber,' oí que me preguntaban” (180)- pero aun queda en el anonimato de la voz pasiva plural. Si bien esta distancia lingüística señala la alienación de Juan Preciado, también subraya una distancia social entre él y Abundio. Abundio finalmente pregunta por el padre de Juan Preciado y anuncia que "yo también soy hijo de Pedro Páramo” (181). Pero se da la impresión de que la pregunta busca confirmar algo ya intuido. Este reconocimiento implícito sugiere la densidad de relaciones sociales sintetizadas entre Juan Preciado y Abundio. Si la relación filial aparece como un eje de la novela, Rulfo inmediatamente lo concretiza al localizar el conflicto en una estructura social específica al campo latinoamericano: el poder patriarcal del hacendado.

La distancia de clase social que separa a Abundio y Juan Preciado se marca en la diferencia entre sus madres, como Abundio aclara después de explicar la extensión de la Media Luna: “nuestras madres nos malparieron en un petate aunque éramos hijos de Pedro Páramo. Y lo más chistoso es que él nos llevó a bautizar” (183). Abundio es doblemente un hijo de la tierra: porque su padre es dueño de "toda la tierra que se puede abarcar con la mirada” (183) y porque nació pobremente en el suelo. Aquí una ironía resulta del choque entre la mirada elevada que define la comarca del patrón y la posición a ras del suelo que define la vulnerabilidad de los peones. Esta ironía hace palpable el odio de Abundio, y el texto introduce así uno de los intercambios más extraños de la novela: “'Con usted debe haber pasado lo mismo, ¿no?’ ‘No me acuerdo’. ‘ Váyase mucho al carajo!’” (183). Cuando Abundio pregunta por el nacimiento de Juan Preciado, pide que éste se defina en términos de clase social. Quizás al notar un resentimiento, Juan Preciado no responde, pero el tono retórico de la pregunta confirma que el arriero sólo quería poner a Juan Preciado en el dilema de negar su origen o marcar su identidad, rompiendo así la "gota de confianza” (182) que Juan Preciado había percibido en él. Al esconder su identidad, Juan Preciado se revela como hipócrita y cobarde, y la respuesta -“¡váyase mucho al carajo!”- viene a ser una de las frases más elocuentes en Rulfo: en el complicado tejido que define a estos dos personajes, la maldición de Abundio condensa la necesidad mutua de la clase dominante y la clase trabajadora -su dependencia- pero también señala el rencor del subalterno y su repudio frente a la mala fe de la clase dominante.

Sin embargo, desde la perspectiva del repudio político no es la maldición que resulta interesante sino lo que sigue: ““¡Váyase mucho al carajo!’ ‘Qué dijo usted?’ ‘Que ya estamos llegando, señor’” (183). La falta de comunicación aquí podría atribuirse a la alienación de Juan Preciado o podría entenderse dentro de las “armas de los débiles” que James Scott estudió: un insulto a sotto voce que el hijo del patrón puede escuchar sin entenderlo bien. También se podría leer el insulto como una represión, algo que Juan Preciado oye sin registrarlo. Pero puede ser menos importante explicar este intercambio que identificar la estructura que se traza entre los dos personajes y sus respectivas clases sociales. La tensión lacónica entre ellos termina en una abierta falta de comunicación: el diálogo se desvanece en un cruce de códigos que recuerda la comunicación política interrumpida por el repudio del subalterno frente a las reglas del juego liberal. La 
importancia del intercambio se revela así en lo que no se dice, porque este silencio registra un rencor del subalterno que corta el circuito de comunicación entre los personajes y, como consecuencia, entre el texto y el lector. Si bien este hueco podría entenderse como el fracaso del discurso letrado frente al subalterno, las dinámicas del repudio permiten leerlo como el registro alegórico de una política popular. En Pedro Páramo, esta alegoría del repudio se construye como un resentimiento generalizado, pero en otros textos de Rulfo la misma dinámica se expresa de una manera más articulada. El mejor ejemplo es "Luvina," el cuento que supuestamente le dio a Rulfo el ambiente narrativo para escribir Pedro Páramo.

"Luvina” es la historia de un maestro rural que, durante la presidencia de Lázaro Cárdenas (1934-40) participa en el programa para la educación socialista. Llega “cargado de ideas” a un pueblo aislado y allí descubre que Luvina está semi-abandonado porque la tierra se ha desgastado y los hombres se han ido. La gente que persiste es enormemente sospechosa del forastero, y después de un período no definido, el maestro, ya en un estado emocional arruinado, también abandona el pueblo. A través de este personaje, el cuento critica un gobierno incapaz de resolver los problemas básicos del campo, supuestamente el alma de la revolución de Zapata. Sin embargo, otros elementos del texto sugieren una historia aun más específica y profunda.

El maestro describe el pueblo diciendo que "de los cerros altos del sur, el de Luvina es el más alto" (102). Después, describe la iglesia como "un jacalón vacío, sin puertas, nada más con unos socavones abiertos y un techo requebrajado” y el "altar desmantelado" (107). La posición estratégica en el punto más alto del entorno junto con la imagen de la iglesia destruida evocan la Guerra Cristera (1927-29), el conflicto religioso que provocó más de 20,000 muertes y definió la niñez de Rulfo. Al sugerir este contexto de fondo, el cuento señala una historia de resistencia frente al estado. Esta historia cifrada ayuda a explicar la respuesta de la gente cuando el maestro sugiere solicitar mejores tierras a través de la reforma agraria: “'Dices que el gobierno nos ayudará, profesor? Tú conoces al gobierno?’ Les dije que sí. ‘También nosotros lo conocemos. Da esa casualidad. De lo que no sabemos nada es de la madre del gobierno'” (110). El maestro responde que la madre del gobierno es la patria, pero la gente de Luvina lo contradice con una de las frases más famosas de Rulfo: "Pelaron sus dientes molenques y me dijeron que no, que el gobierno no tenía madre” (110). El mismo narrador desglosa la frase, explicando que el gobierno "sólo se acuerda de ellos cuando alguno de sus muchachos ha hecho alguna fechoría acá abajo. Entonces manda por él hasta Luvina y se lo matan” (110). Es decir, la relación entre el pueblo y el estado se reduce al castigo criminal. Pero el contexto implica un desconocimiento mayor frente al gobierno. Para una comunidad que ha sobrevivido la revolución y la Cristiada, decir que el gobierno no tiene madre es otra manera de rechazar un estado que no cabe dentro de las estructuras que definen la legitimidad política y la autonomía social del pueblo. Se trata de las mismas estructuras que definen la representatividad de Zapata: las tradiciones locales, el sufrimiento compartido y, de manera elocuente aquí, el parentesco. Cuando la comunidad se rehusa a recibir al maestro como un agente del progreso y le explican que para ellos, el gobierno no tiene madre, el odio generalizado de Abundio cobra un sentido más explícitamente político y aun más cercano a las dinámicas del repudio subalterno frente a la política liberal. Es, quizás, en 
este sentido que Juan José Arreola, uno de los mejores amigos de Rulfo, lo caracterizó como "un administrador fabuloso del rencor popular” (citado en Martin 496).

Con esta lectura de Rulfo, apenas bosquejada, no quiero reemplazar una metacrítica subalternista con un proyecto mimético. Resulta poco interesante preguntar si Rulfo registra bien la cultura campesina. Mi propósito es más bien explorar cómo los textos de Rulfo subvierten las estructuras que mediatizan la política popular, ubicando así al lector fuera de las posiciones acostumbradas en la literatura mexicana. Con esto, Rulfo plantea la posibilidad de una literatura atenta al proceso hegemónico y a la lucha por establecer los límites de la historia colectiva.

Conclusiones

Al distanciarse de Mallon, Beverley ha cuestionado el vínculo que ella sugiere entre los sectores populares y el discurso nacionalista. "Para emplear una metáfora lacaniana”, dice, “esto ‘sutura' un hiato social y conceptual que en cierto sentido sería mejor dejar abierto. De ahí que Peasant and Nation en parte oculte precisamente lo que quiere hacer visible: las dinámicas de Negación en la agencia subalterna” (Subalternity 36). Esta crítica recuerda la separación histórica que Guha vio entre la política popular y el nacionalismo en la India, pero en este punto también habrá que tomar en cuenta el detallado análisis con el cual Mallon sugiere que Latinoamérica no ha seguido las líneas de ciertos estudios dominantes sobre el nacionalismo. En particular, el modelo de Benedict Anderson propone al nacionalismo cómo un fenómeno divulgado desde arriba en la estructura social a través de la imprenta, pero Mallon sugiere la posibilidad de entender el nacionalismo como un fenómeno pactado entre la élite y las clases populares. Como Claudio Lomnitz ha señalado, el capítulo de Comunidades imaginadas dónde Anderson trata Latinoamérica es particularmente débil en términos de sus fuentes y argumentación. El modelo de Mallon bien podría sugerir una alternativa basada en las precisiones de un análisis histórico que no recae en escencialismo, como la "particularidad” de Latinoamérica.

Habrá que notar también que la descripción de Peasant and Nation como un esfuerzo para hacer visible las dinámicas de negación en la agencia subalterna no corresponde al lenguaje de Mallon. Esta diferencia puede atribuirse a un desencuentro conceptual alrededor de la negación. Beverley ha afirmado que "para Guha, como para Lacan, la categoría que define la identidad o la voluntad subalterna es la Negación” (Subalternity 26). Quizas ayude especificar que para Guha, el concepto de la negación es más social que semiológico, en el sentido de referir directamente a las relaciones entre grupos y no a la constitución de la subjetividad discursiva y lingüística. En este mismo orden de las cosas, Guha incluye la negación como uno de seis aspectos básicos de la insurgencia campesina y, por lo tanto, el impacto de la negación sobre el terreno de la semiología social requiere de cierta especificidad histórica.

El propio Guha es quien define la negación como una categoría de la "conciencia negativa de clase”, una formulación tomada del famoso estudio Bond Men Made Free (1973). En este libro clásico de la historiografía marxista, Rodney Hilton examina las revueltas campesinas en la Europa medieval para arrojar una luz nueva sobre la composición del campesinado como una clase social importante para entender la transición del 
feudalismo al capitalismo temprano. El propio Hilton anunció el tema de su trabajo como una intevención velada en el análisis del campesinado en las "colonias formales o informales, que constituyen la mayoría del llamado 'tercer mundo””, países por entonces "inmersos en acciones revolucionarias” para los cuales el campesinado representaba un sector social de suma importancia (9). ${ }^{12}$ Guha cita a Hilton quizás en solidaridad con este elemento alegórico de su estudio: “A pesar de todas las disimilitudes en otros aspectos, 'había un rasgo prominente que [estas revueltas] tenían en común': 'la emergencia, entre algunos participantes, de una conciencia de clase. Era, sin embargo, una conciencia negativa de clase en que la definición de clase social era la de sus enemigos y no de ellos mismos"” (Guha 20; Hilton 30-31). Esta conciencia negativa de clase opera cuando un sector entiende su posición social desde la óptica del opresor. El resultado es un deseo de invertir la jerarquía social o negar la subordinación para asumir la posición dominante tal como ésta está constituida en el orden actual de las cosas. Guha señala directamente los límites de tal conciencia:

Tomado aisladamente esto por supuesto no podría constituirse como una conciencia de clase madura y plena. Pero sería igualmente erróneo no verlo como el mero comienzo de dicha conciencia. Gramsci nos ayuda a entender su momento preciso al caracterizarlo "meramente como el primer brillo de tal conciencia, es decir, meramente como su aptitud básica, negativa, polémica”. Ahora bien, con todas sus precauciones de no sobreestimarlo, él reconoce su importancia como un comienzo necesario. (Guha 19)

Es decir que para Guha la conciencia negativa de clase representa un comienzo para la agencia subalterna. Se trata de un comienzo que en sí resultó insuficiente para derrocar el régimen colonial en la India. De ahí surge la descripción “elementales” en su título: para indicar una fase en la lucha anti-imperial, pero una fase preliminar al cambio duradero. El propósito de su proyecto está en esto: estudiar las modalidades de la cultura popular para mejorar las articulaciones entre las diversas facciones del subalterno y formar así un bloque histórico capaz de alterar el proceso hegemónico de manera permanente.

En sí, el repudio no puede entenderse como una característica restringida a la política popular latinoamericana, pero su expresión en la narrativa de Rulfo demuestra cómo la literatura registra elementos de una agencia subalterna en términos derivados de una historia específica. Además, si el repudio claramente representa una dinámica cercana a la negación en Guha, el repudio surge de una conciencia de clase más articulada. El campesinado en Morelos había tenido una experiencia política variada y, aun más

\footnotetext{
${ }^{12} \mathrm{El}$ uso de estudios sobre el período medieval para entender las culturas campesinas modernas resulta bastante común en los trabajos sobre cultura popular, sobre todo en términos de la naturaleza de la oralidad. Véase, por ejemplo, el provecho que Antonio Cornejo Polar saca de los estudios de Paul Zumthor sobre la poesía y la oralidad medieval (Cornejo Polar 60). La explicación podría ser algo que el propio Rodney Hilton notó: que existe mayor documentación escrita sobre la vida cotidiana del campesinado medieval en Europa que sobre cualquier otro grupo semejante de agricultores (Hilton 11). Habrá que recordar, finalmente, que se trata de una relación mutua, en la cual los medievalista también hacen uso de estudios etnográficos sobre comunidades agrarias en el "tercer mundo" como modelos para el campesinado medieval (Zumthor 64).
} 
específicamente, un contacto extendido con los límites de la democracia liberal. Además, como Guha señala, las seis modalidades de insurgencia campesina que él identifica para la India corresponden, en su más extensa raigambre social, a la omnipresencia de la relación peón-terrateniente como un eje de la estructura económica y política. Dicha estructura "tenía sus raíces en la relación de dominio y subordinación característica de la sociedad de la India durante un período muy largo, antes y después del régimen colonial”. Estas formas de propiedad produjeron modelos de autoridad todavía activos, lo cual explica la actualidad del campesinado como paradigma de la insurgencia popular: "mientras la autoridad del terrateniente siga funcionando como un elemento significativo en la cultura de los dominadores -y seguirá funcionando por mucho tiempo aun después del final genuino [...] en la economía y en las relaciones de propiedad-todas las luchas tenderán inevitablemente a articularse" a través de las modalidades elementales de la insurgencia campesina (Guha 335-36). Para el caso de Zapata (y América Latina en general), habrá que especificar las formas de autoridad depositadas en la estructura social a través del sistema de propiedad y la manera en que estas formas coinciden con sus propias modalidades de insurgencia campesina. En Morelos, por ejemplo, habrá que tomar en cuenta la importancia de las comunidades autónomas y su historia de autodefensa frente a las haciendas como un detentor crucial de las negociaciones entre una élite que promovía cierta visión modernizadora y las clases populares que deseaban preservar estructuras sociales que les habían garantizado cierto grado de independencia a la vez que les habían propiciado cierto grado de participación en el discurso político.

En este contexto, donde el sistema político dominante ha tenido que ofrecer ciertas aberturas a las demandas populares, la experiencia de participar brevemente en el proceso hegemónico tendió a producir relaciones de clase más determinantes que las relaciones que Guha deliminta para sus aspectos elementales de la insurgencia campesina. Con esta conciencia de clase, desarrollada bajo los fracasos de la democracia liberal y la imposición de un nuevo modelo económico, el repudio buscaba lo contrario de una simple inversión o negación de la jerarquía social: buscó construir un sistema alternativo para corregir los abusos de la clase dominante y plantear un orden político más vinculado con la voluntad popular. Se podría postular, inclusive, que la larga experiencia de lucha y negociación que se dio en el contexto de las comunidades autónomas de Morelos en la segunda mitad del siglo xIX permitió que la política subalterna llegara a una conciencia más clara de la convergencia entre una estructura agraria básicamente arcaica (la concentración de la tierra), cierta modernización económica (la comercialización de la agricultura) y la democracia liberal (las elecciones periódicas). Lo que está en tela de juicio era precisamente la continuidad de esta coyuntura que tanto daño había hecho a un campesinado todavía no convertido en proletariado rural. El repudio señala la conciencia de clase que surgió cuando esta coyuntura entró en crisis, junto con una aguda crítica de las relaciones sociales dentro de un sistema de dominación que quería alterarse económicamente a la vez que mantenía sus antiguas formas de privilegio y los mismos canales para ejercer el poder.

El futuro trabajo de un subalternismo literario podría encontrarse en este tipo de enlaces entre teorías ya desarrolladas para otros contextos con las realidades locales de Latinoamérica. Hasta recientemente el subalternismo literario para América Latina ha rastreado una anti-dialéctica del sujeto popular, es decir, su negación a constituirse como 
un sujeto bajo la epistemología social dominante. Pero al identificar este momento en la agencia subalterna, habrá que evitar también la consecuencia final que Stuart Hall notó en la prácticas deconstruccionistas: su incapacidad de vislumbrar ideologías concretas sino como simples instancias del poder existente (Hall 161-62). En otras palabras, habrá que plantear no solamente el problema del dominio, sino también el de la hegemonía.

BibLiografía

Achugar, Hugo. "Leones, cazadores e historiadores, a propósito de las políticas de la memoria y del conocimiento”. Revista Iberoamericana LXIII/180 (1997): 379-387.

Beverley, John. "The Im/possibility of Politics: Subalternity, Modernity, Hegemony”. The Latin American Subaltern Studies Reader. Ileana Rodríguez, ed. Durham: Duke University Press, 2001. 47-63.

Subalternity and Representation. Durham: Duke University Press, 1999.

“Cultural Studies”. Latin American Literary Review 20/40 (1992): 19-22.

Bravo, Víctor. “¿Post-Coloniales Nosotros?” Voz y Escritura 6/8-9 (1999): 237-62.

Carr, Robert. "Elitism and the Death of Subaltern Studies”. LASA Forum 33/2 (2002): 12 13.

Chaturvedi, Vinayak, ed. Mapping Subaltern Studies and the Post Colonial. London: Verso, 2000.

Cornejo Polar, Antonio. Escribir en el aire. Berkeley, CA: Centro de Estudios Literarios Antonio Cornejo Polar/Latinoamericana Editores, 2003.

Guha, Ranajit. The Elementary Aspects of Peasant Insurgency. New Delhi: Oxford University Press, 1983.

Hall, Stuart. "Recent Developments in Theories of Language and Ideology". Cultura, Media, Language. Working Papers in Cultural Studies, 1972-79. S. Hall et al. Hutchinson/University of Birmingham Centre for Contemporary Cultural Studies, 1980. 157-62.

Hilton, Rodney. Bondmen Made Free. Medieval Peasant Movements and the English Rising of 1381. London: Temple Smith, 1973.

Joseph, Gilbert y Daniel Nugent, eds. Everyday Forms of State Formation. Revolution and the Negotiation of Rule in Modern Mexico. Durham: Duke University Press, 1994.

Katz, Friedrich. The Life and Times of Pancho Villa. Stanford: Stanford University Press, 1998.

Knight, Alan. "Subalterns, Signifiers, and Statistics: Perspectives on Mexican Historiography”. Latin American Research Review 37/2 (2002): 136-58.

Kokotovic, Misha. "Intellectuales and Their Others: What is to Be Done?” Diaspora 9/ 2 (2000): 287-308.

Latin American Subaltern Studies Group. “Founding Statement”. boundary 2 20/3 (1993): 110-21.

List Arzubide, Germán. Emiliano Zapata (exaltación). México: Ediciones Conferencia, 1965. 
Lomnitz, Claudio. “Nationalism as Practical System: Benedict Anderson’s Theory of Nationalism from the Vantage Point of Spanish America”. Deep Mexico, Silent Mexico. Minneapolis: University of Minnesota Press, 2001. 3-34.

López y Fuentes, Gregorio. Tierra. En La novela de la revolución mexicana. Antonio Castro Leal, ed., vol. 3. México, DF: Aguilar/SEP, 1988. 250-304.

Magaña, Gildardo. Emiliano Zapata y el agrarismo en México. México: Instituto Nacional de Estudios Históricos Sobre la Revolución, 1985.

Mallon, Florencia. Peasant and Nation. The Making of Post-Colonial Mexico and Peru. Berkeley: University of California Press, 1994.

“The Promise and Dilemma of Subaltern Studies". American Historical Review 99/ 5 (1994): 1491-1515.

Martin, Gerald. "Vista panorámica: la obra de Juan Rulfo en el tiempo y en el espacio”. Toda la obra. [1992]. En Juan Rulfo. México, DF: UNESCO/Colección Archivos 17, 1996. 573-647.

Moraña, Mabel. “El Boom del subalterno”. Revista de Crítica Cultural 14 (1997): 48-53.

O’Malley, Ilene V. The Myth of the Mexican Revolution. West Port, CT: Greenwood Press, 1986.

Rabasa, José. "Beyond Representation? The Impossibility of the Local”.The Latin American Subaltern Studies Reader Ileana Rodríguez, ed. Durham: Duke University Press, 2001. 191-210.

Rama, Ángel. La ciudad letrada. Hanover, NH: Ediciones del Norte, 1984.

Rodríguez, Ileana. “A New Debate on Subaltern Studies?” LASA Forum 33/2 (2002): 1011.

Rojeck, Chris. Stuart Hall. London: Polity Press, 2003.

Roseberry, William. “Hegemony and the Language of Contention”. en Joseph y Nugent, 355-66.

Rulfo, Juan. Toda la obra. Claude Fell, ed. México: UNESCO/Colección Archivos, 1996. Scott, James C. Weapons of the Weak. Everyday Forms of Peasant Resistance. New Haven: Yale University Press, 1985.

Vaughn, Mary Kay. “Cultural Approaches to Peasant Politics in the Mexican Revolution”. Hispanic American Historical Review 79/2 (1999): 269-305.

Warman, Arturo. “The Political Project of Zapatismo”. Riot, Rebellion, and Revolution. Friedrich Katz, ed. Princeton, NJ: Princeton University Press, 1988. 321-37.

Womack, John. Zapata and the Mexican Revolution. New York: Vintage, 1970.

Zumthor, Paul. La lettre et la voix. De la “littérature” médiévale. Paris: Éditions du Seuil: 1987. 